\title{
Porites white patch syndrome: an unreported coral disease on Western Indian Ocean reefs
}
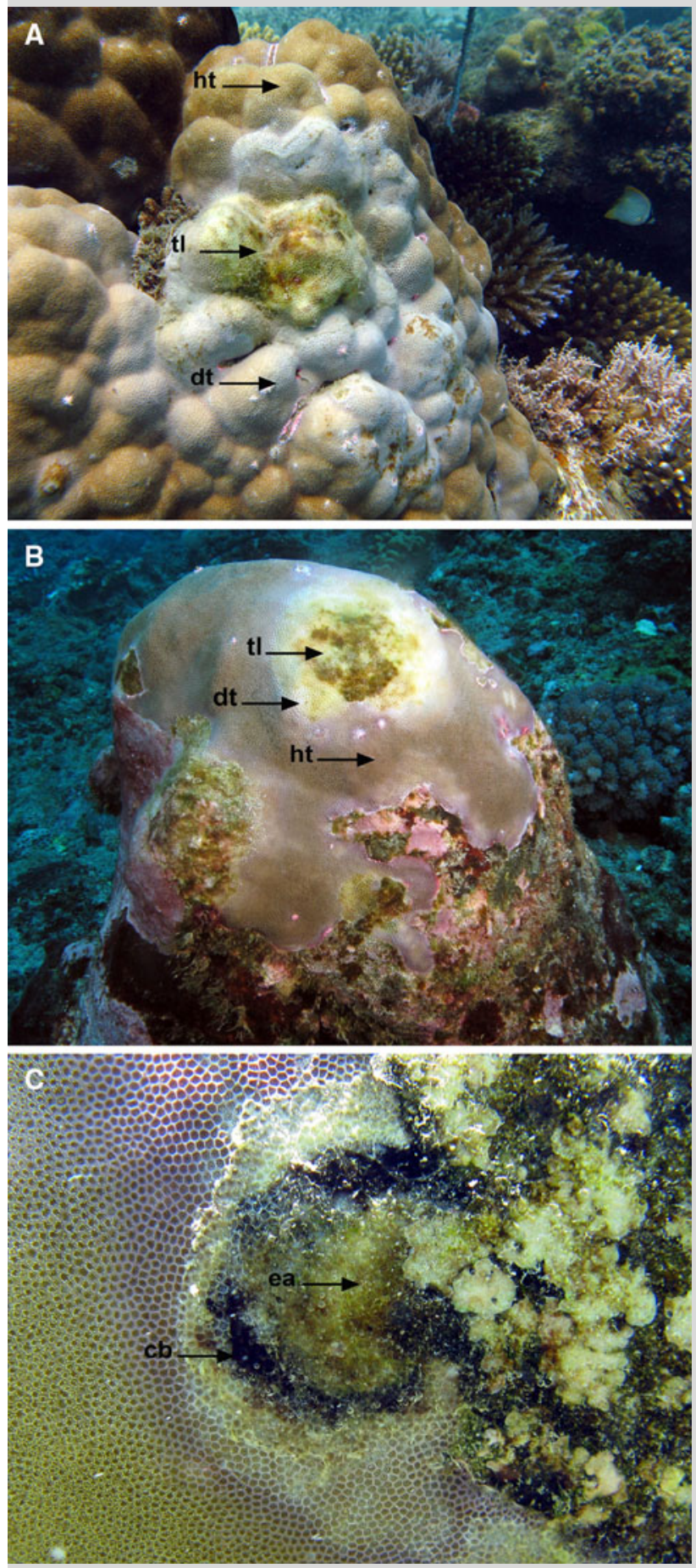

Fig. 1 Porites white patch syndrome on a Porites lobata and b P. lutea, showing healthy (ht), diseased (dt) and an area of tissue loss (tl). c PWPS colonized by epilithic algae (ea) and cyanobacteria (cb)
Coral diseases affecting reef-building corals in the Western Indian Ocean (WIO) are not well documented compared to those in the Caribbean. Surveys conducted at multiple sites (within five $10 \times 2 \mathrm{~m}$ belt transects, perpendicular to the shore) in both Reunion Island $\left(21^{\circ} 07^{\prime} \mathrm{S}, 55^{\circ} 32^{\prime} \mathrm{E}\right)$ and South Africa (Sodwana Bay, Two-mile Reef, $21^{\circ} 48.211^{\prime} \mathrm{S}$, $35^{\circ} 30.156^{\prime} \mathrm{E}$ ) from July 2010 to June 2011 revealed the presence of a previously unreported coral disease condition: Porites white patch syndrome (PWPS) (Fig. 1). This syndrome was found only on massive Porites lobata and P. lutea (Fig. 1a, b). Following standardized terminology (Work and Aeby 2006), PWPS is characterized by diffuse, medium to large (5.0-30.0 cm diameter), circular to oblong tissue loss, surrounded by a $1.0-20.0 \mathrm{~cm}$ width zone of swollen, paler tissues. The older exposed skeleton is progressively colonized by epilithic algae and cyanobacteria (Fig. 1c). It was observed at most survey sites. At Reunion Island, $6.4 \%$ of the 1947 P. lutea colonies recorded on the fringing reef (0.5-1 m deep) to the outer slope (9-15 m deep) had signs of PWPS. In South Africa (9-12 m deep), $2.5 \%$ of the $152 P$. lutea colonies surveyed were affected. Histological and molecular studies on this disease condition are in progress.

Acknowledgments This research was funded by the European Union (EU), Direction de l'Environement, de l'Aménagement et du Logement (DEAL), Délégation Régionale à la Recherche et à la Technologie (DRRT) and la Région Réunion, with support of Fonds Européen de Développement Régional (FEDER), and the Western Indian Ocean Marine Science Association (WIOMSA). Thanks are also due to Professor John Bythell (University of Newcastle) for his valuable comments and Stéphanie Bollard (Agence pour la Recherche et la Valorisation Marine, ARVAM).

\section{Reference}

Work T, Aeby G (2006) Systematically describing gross lesions in corals. Dis Aquat Org 70:155-160

M. G. Séré $(\bowtie)$ · J. P. Quod

ARVAM, 2 rue Maxime Rivière, CYROI, Technopole de La Réunion, 97490 Ste Clotilde, Reunion Island, France

e-mail: mathieu.sere@ arvam.com

\section{H. Schleyer}

Oceanographic Research Institute (ORI), Marine Parade, PO Box 10712, Durban 4056, South Africa

\section{P. Chabanet}

Institut de Recherche pour le Développement (IRD), Centre Réunion, BP 172, 97492 Sainte Clotilde Cedex, Reunion Island, France 